\title{
Management of Colles' Fracture bv Conservative vs Open Reduction Bone Grafting and Internal Fixation with K-wire
}

\author{
Khan JA. ${ }^{1}$ Mahara DP 1 \\ ${ }^{1}$ Department of Orthopaedics. Patan Hospital. ${ }^{2}$ Dedartment of Orthopaedics. TUTH
}

\begin{abstract}
Background: Colles' fracture is commonlv encountered fracture in emeroencv department. Maioritv of cases are bein $\sigma$ treated bv conservative means that often leads to deformitv and instabilitv. We compared the treatment outcome of open reduction and bone oraftin $\sigma$ with conventional close reduction and cast application.

Methods: This prospective studv was carried out in two different centers from September 2002 to September 2004. There were 41 patients included in the studv. There were 24 patients in conservative group and 17 patients in operative group. All patients were followed un to twelve weeks. At six months follow un onlv 19 patients were available in conservative oroup and 16 patients in operative group. We observed anatomical and functional outcome in both oroups immediatelv after reduction. at six weeks. at twelve weeks and at six month.

Results: Reduction can be achieved in both groups but at the final follow un there was significant collanse observed in conservative oroup. There was a sionificant improvement in the dorsal angle: radial anole and radial lenoth at six months follow un in operative group. Functional results in terms of pain. ran $e_{e}$ of motion and $ø$ rip strenoth were also observed better in operative oroups but this difference was not statisticallv sionificant. In operative group one case developed non-union and in conservative oroun two cases developed reflex svmpathetic dvstrophv.

Conclusion: This studv shows that the open reduction and tricortical bone grafting in Colles' fracture treatment gives better anatomical results than in conservative groups. There is no sionificant difference in function at short term if there is no malunion.
\end{abstract}

Kev words: fracture: open reduction: bone oraftin $\%$ : close reduction

\section{INTRODUCTION}

Distal radius fracture is verv common. estimated to account for un to $1 / 6^{\text {th }}$ of all fractures. The incidence of complications. which includes stiffness and loss of reduction. has been reported to be as high as $31 \%{ }^{1}$ Despite, our use of more elaborate treatment methods. there are still disabling svmptoms of pain. deformitv. stiffness. and nerve combression svndromes associated with distal radial malunion. This fracture is inherentlv unstable due to comminution of dorsal cortex and tapering shape of the radius. Collapse is inevitable while fracture is healing unless there is good dorsal support. Based on this concept tricortical bone graft was used to fill dorsal comminution and further fixation was done with trans- stvloid k-wire. Closed reduction and 
cast immobilization invariablv leads to Door functional outcome due to re-displacement of fracture within the cast. ${ }^{2}$ The purpose of the studv is to evaluate the results of this techniaue in fractures of the distal end of radius and to combare it with the results of closed manibulative reduction and plaster cast immobilization. We compared the anatomical and functional outcome of this technique with that of the conventional close reduction and cast apdlication for distal radius fracture.

\section{METHODS}

This is prospective combarative clinical trial conducted in the departments of Orthopedics at two different centers from Sedtember 2002 to Sedtember 2004. After Ethical approval and patient consent 41 patients aged 40 and above with displaced. extra-articular distal radius fractures (Frvkman tvpe I and II) having normal contra-lateral wrist were enrolled in this studv. These patients were randomlv divided into two groups. Twentv four of them were treated conservativelv with close reduction followed bv below elbow cast for six weeks and other group included 17 patients who underwent open reduction combined with tricortical bone grafting and trans-stvloid k-wire fixation. Patients with increased risk of anesthetic hazards were considered for close reduction. All batients came for follow un to 12 weeks. At six months follow un onlv 19 patients were available in conservative groun. Two patients expired of their medical illness and three patients could not be traced. In operative groun one batient did not come for follow up.

\section{Close reduction and cast immobilization groun:}

Normal side wrist X-rav wrist was taken for combarison. Reduction was done under general or regional anesthesia with patient in supine position. shoulder was abducted and elbow flexed. Traction was applied to the thumb with counter traction above the elbow. When traction alone was not sufficient to correct then surgeon manipulated bv compression. Reduction was ascertained clinicallv and radiologicallv. After satisfactorv reduction (dorsal angle $<10$ degree. radial angle $<5$ degree of the normal side and radial shortening $<5 \mathrm{~mm}$ of normal side.) colles cast was applied. Check $X$ rav was performed immediatelv after reduction. Thev were followed up in next dav in OPD to check for Dlaster comblications and were subsequentlv followed un weeklv for three consecutive weeks. At each follow uD. AP and lateral X rav were done to note earlv deformitv. At six week. cast was removed and active range of motion (ROM) exercise of the wrist was started and anatomical and functional outcome was assessed. At 12 week Dain. deformitv. ROM and grip strength was assessed including radiological assessment. At six months the final evaluation of anatomical and functional outcome was done. The methods of anatomical and functional evaluation are mentioned at the end of this section.

\section{Open reduction internal fixation with cortico cancellous bone grafting groud.}

We followed the original techniaue described bv McBirnie et al. ${ }^{3}$ All procedures were carried out in the operation theater under general anesthesia. Tricortical bone graft was harvested bv a second team from opdosite iliac crest. After abdlving the tourniauet a transverse incision was made on the dorsum of wrist down to the extensor retinaculum at the level of fracture. A longitudinal incision was made in the extensor retinaculum at third extensor compartment. Fracture site was identified and elevated. This left a defect in the dorsal cortex. which was filled bv a triangular wedge of cortico-cancellous bone taken from the opdosite iliac crest.

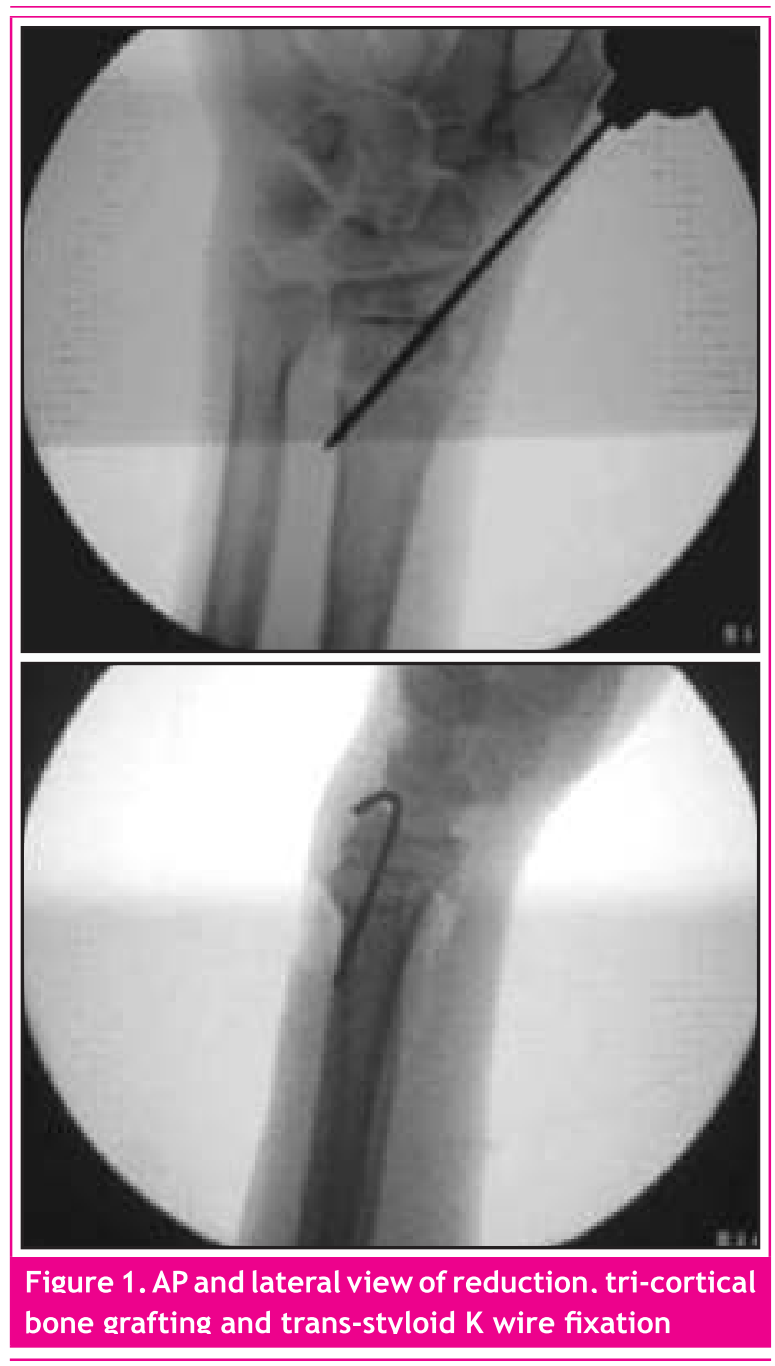


AK-wire was inserted through the radial stvloid diagonallv across the distal radius engaging the graft and the more proximallv the medial cortex of the radius under the guidance of image intensifier (figure 1). Wound was closed in single laver and below elbow cast was applied with wrist in neutral position. Check $X$ rav was made in AP and lateral view immediatelv after cast apdication. Patient was discharged on third post operative dav after wound inspection.

Intravenous antibiotics were used till patient was in hospital and oral antibiotics for a further seven davs. Sutures were removed on $14^{\text {th }}$ post operative dav. Weeklv follow un for three weeks were done for AP and lateral view $X$ ravs. Next follow un was after six weeks when the cast and pins were removed and AP and lateral $x$ -ravs were taken. Functional evaluation was also done as in groun one. Anatomical and functional evaluation was Derformed at $12^{\text {th }}$ weeks and finallv at six months.

\section{Anatomical evaluation-}

All measurements were done bv the X-ravs method described bv Vander Linden. Values were compared with normal wrist. ${ }^{4}$ Shifts measured as difference from normal side.

a) Dorsal angle in degrees

b) Dorsal shift in millimeters

c) Radial angle in degrees

d) Radial shift in millimeters

e) Radial length in millimeters

Functional evaluation ${ }^{5}$

Pain:

Grade I (no pain)

Grade II (bain on extreme of motion.)

Grade III (Dain on normal activitv

Grade IV (bain at rest)

Range of motion: Combared with the normal wrist and expressed as Dercentage of normal motion.

Grip Strength: Measured with Novartis grin meter and expressed in percentage of normal side.

\section{Statistical analvsis}

Data was processed and analvzed bv undaired t-test. Independent sample t-test for comparison of means. All statistical analvsis was done using SPSS 11.5 program for Windows. $P$ values less than 0.05 was taken as statisticallv significant.

\section{RESULTS}

\section{Anatomical results}

Our result revealed statisticallv significant difference in achieving the radial length. Other Darameters though better restored in operative groun were not statisticallv significant (Table 1).

At six months follow up. restoration of dorsal angle. radial angle and radial length were significant. Other parameters were better in operative groun but differences were not significant which revealed better restoration of distal radius anatomv in the operative groun (Table 2 ).
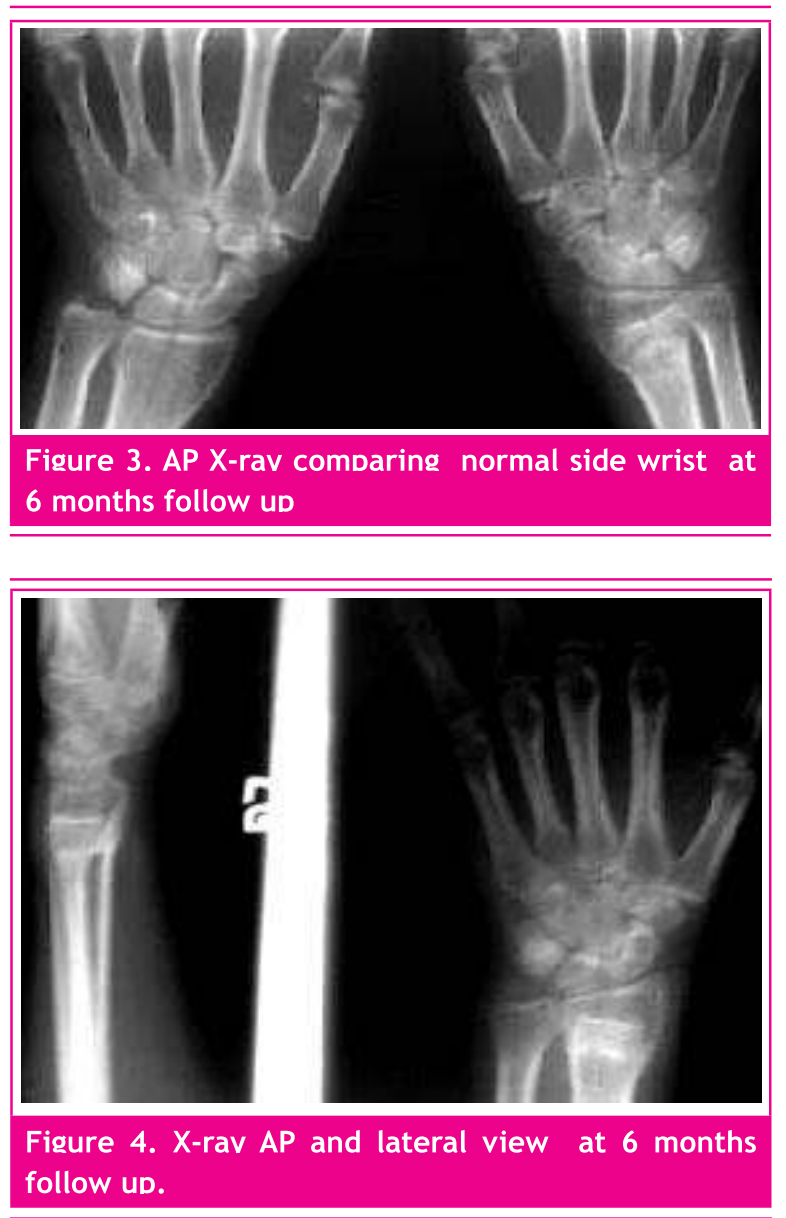

There was significant loss of dorsal angle. radial angle and radial length in conservative group after 6 months as combare to immediate reduction. (Table 3 ).

In operative groun there was some collabse but difference was not significant indicating that in operative group reduction was better maintained. (Table 4)

\section{Functional evaluation at six months follow ud:}

All Darameters in functional evaluation were better in operative groups but none of them were statisticallv significant.

Two patients in conservative groun develoned reflex svmbathetic dvstrophv. Two patients in operative 
Management of Colles' Fracture bv Conservative...

group developed superficial marginal wound necrosis. No batient developed infection. bone graft donor site One patient developed non-union in operative groups. problem. compression neuropathv or tendon rupture.

\begin{tabular}{|c|c|c|c|}
\hline & Conservative group $(\mathrm{N}=\mathbf{2 4})$ & Operative group $(\mathrm{N}=17)$ & $P$ value \\
\hline Dorsal angle (degrees) & -1.54 & -4.11 & 0.335 \\
\hline Radial angle (degrees) & 19.33 & 20.41 & 0.56 \\
\hline Dorsal displacement $(\mathrm{mm})$ & 2.16 & 1.17 & 0.22 \\
\hline Radial displacement (mm) & 1.83 & 1.47 & 0.49 \\
\hline Radial length $(\mathrm{mm})$ & 7.33 & 10.05 & 0.001 \\
\hline
\end{tabular}

Table 2. Anatomical results at 6 months follow up.

\begin{tabular}{|lccc|}
\hline & Conservative group $(\mathrm{N}=19)$ & Operative groud $(\mathrm{N}=16)$ & $P$ value \\
\hline Dorsal angle (degrees) & -2.68 & -3.75 & 0.05 \\
Radial angle (degrees) & 15.94 & 19.56 & 0.006 \\
Dorsal displacement $(\mathrm{mm})$ & 1.52 & 0.50 & 0.22 \\
Radial displacement $(\mathrm{mm})$ & 2.68 & 1.87 & 0.15 \\
Radial length $(\mathrm{mm})$ & 4.42 & 6.56 & 0.05 \\
\hline \hline
\end{tabular}

Table 3. Combarison of anatomical results after immediate reduction and after 6 months

\begin{tabular}{llll|}
\hline Conservative groud $(\mathrm{N}=16)$ & Immediate after reduction & At six months & P value \\
\hline Dorsal angle (degrees) & -1.54 & -2.68 & 0.033 \\
Radial angle (degrees) & 19.33 & 15.94 & 0.000 \\
Dorsal disblacement $(\mathrm{mm})$ & 2.16 & 1.52 & 0.855 \\
Radial displacement $(\mathrm{mm})$ & 1.83 & 2.68 & 0.187 \\
Radial length $(\mathrm{mm})$ & 7.33 & 4.42 & 0.000 \\
\hline \hline
\end{tabular}

Table 4. Comparison of anatomical results immediatelv after surgerv and after 6 months.

\begin{tabular}{|llll|}
\hline Operative group $(\mathrm{N}=19)$ & Immediate after reduction & At six months & P value \\
\hline Dorsal angle (degrees) & -4.11 & -3.75 & 0.714 \\
Radial angle (degrees) & 20.41 & 19.56 & 0.001 \\
Dorsal disblacement $(\mathrm{mm})$ & 1.17 & 0.50 & 0.378 \\
Radial displacement $(\mathrm{mm})$ & 1.47 & 1.87 & 0.382 \\
Radial length $(\mathrm{mm})$ & 10.05 & 6.56 & 0.035 \\
\hline \hline
\end{tabular}

Table 5. Functional evaluation at six months follow ud.

\begin{tabular}{|llll|}
\hline & Conservative groun $(\mathrm{N}=19)$ & Oderative groun (N=16) & $P$ value \\
\hline Pain (Grade) & 1.15 & 1.06 & 0.65 \\
Dorsiflexion (\%of normal) & 74.89 & 78.06 & 0.57 \\
Palmarflexion (\%of normal) & 85.31 & 91.50 & 0.18 \\
Radial deviation (\%of normal) & 79.57 & 84.93 & 0.33 \\
Ulnar deviation (\%of normal) & 87.00 & 87.81 & 0.92 \\
Grid strength (\%of normal) & 81.05 & 85.50 & 0.38 \\
\hline \hline
\end{tabular}




\section{DISCUSSION}

Distal radius fractures are verv common and expectations for recoverv are usuallv high. Manv redorts testifv to the good results to be expected from treatment of a Colles' fracture. ${ }^{6-8}$ Even Colles said that the iniured limb would eventuallv regain "Derfect freedom in all its motions." Optimism regarding the outcome of distal radial fractures has pervaded our thoughts regarding the Colles' fracture and deemphasized vigorous treatment. ${ }^{6.7 .10}$ Certainlv. manv Datients will do quite well with an imperfectlv aligned Colles' fracture as has been pointed out manv times. including the report bv Lucas and Sachtien in 1981. ${ }^{11}$ However. some patients will have disabling svmptoms from a healed malaligned fracture. ${ }^{78.11-13}$ Preciselv how much malalignment can be tolerated bv the wrist ioint has not been determined. but certainlv some imperfection is not incompatible with long-term satisfactorv function. ${ }^{11.14-16} \mathrm{~A}$ studv bv Short et al demonstrates fairlv conclusivelv. bv pressuresensitive film measurements. that loss of normal balmar tilt after simulated radial fracture leads to progressive load on the ulnocarbal and radioscaphoid ioints. ${ }^{15}$ Loads become concentrated along the dorsal rim of the articulation. resulting in pain and ultimatelv ioint degeneration. ${ }^{15}$ Their studv demonstrates that at 40 degrees of dorsal tilt. the maioritv of load is carried bv the distal ulna. which thev believe contributes to pain and earlv degenerative ioint disease develonment. Radial shortening has also been described as causing the greatest change in the distal radio-ulnar ioint mechanics leading to distortion of the triangular fibrocartilage. ioint stiffness and imbairment of function with increased risk of permanent disabilitv. ${ }^{14.17}$ Therefore. radial length should be restored as close as possible. The develonment of midcarbal instabilitv following mal-united fractures of the distal radius has also been described. ${ }^{16}$ Obviouslv. the sDectrum of problems with anv sort of distal radial malunion is a continuum. Although anatomic alignment is not the onlv factor influencing the clinical result in a Colles' fracture. it is assumed that anatomic reduction will contribute greatlv to improved results.

In our studv we used tricortical bone graft to fill the dorsal communition. The use of a block of corticocancellous bone block rather than small fragments of cancellous bone gives sufficient stabilitv without the need for external fixation. Bone grafting is reauired for mechanical support rather than to stimulate healing. Earlv open reduction and bone grafting have the advantage over closed techniaues of restoring the volar tilt. Ligamentotaxis has been shown to be an unreliable method of achieving this both in experimentallv and in clinical practice. ${ }^{18.19}$ Restoration of palmar tilt mav be significant in restoring normal function since loss of the normal balmar tilt mav cause carbus to collapse dorsallv. ${ }^{16}$
After close reduction or open reduction there was no statistical significant difference in anatomical Darameters. This indicates that reduction is not a problem in maioritv of cases. Radial length is better restored in bone grafting groups as graft had given support to dorsal comminuted cortex. Our results of reduction is in accordance with McOueen et al who stated that in 95\% cases close reduction is successful. ${ }^{20}$ At six months follow un anatomical results were better in operative groups as there was significantlv better restoration of dorsal angle and radial length. The functional outcome was not significantlv different. We believe on the basis of our studv that if mal-alignment is not significant short term functional outcomes are comparable. There are significant numbers of literature from the time of Abraham Colles to support this hvpothesis. ${ }^{11.21 .22}$ Our results contradict reports bv McQueen et al and Villar et al where thev showed direct correlation between anatomical reduction and range of motion and grip strength. $^{23.24}$ Two patients who develoded reflex svmbathetic dvstrophv in conservative group showed persistence of pain and reduced range of motion. In operative grouns one batient developed non-union and gave boor result. The overall result shows operative group is better than conservative groups.

We encountered significant loss of reduction in terms of radial angle and radial length in both grouns but dorsal angle was preserved in operative grouns. This finding indicates that there will be some collapse even with this techniaue. Two Datients who developed reflex svmbathetic dvstrophv in conservative groups were treated with phvsiotherapv. No case developed carpal tunnel svndrome or anv case suggestive of carbal instabilitv or ulno-carbal impingement was found. No case of tendon rupture was observed in our series as this is an uncommon comblication which takes place after six to nine months of fracture. No infection was noticed in our series but there were onlv marginal skin necroses at the surgical margin in two earlv cases which were because of small skin incision and inadvertent retraction. In subseauent cases care was taken and no necrosis noticed.

Nonunion was found in one patient at six months. The cause we attribute retrospectivelv to comminution of volar cortex and graft was inserted in between. Literallv there was no contact between proximal and distal fracture fragments. Union was solelv dependent upon resobtion and revascularisation of graft. The graft being tricortical in nature. cortical surface was facing towards fracture ends revascularisation was not possible. When we opened non-union site it was noticed that non-union was at the proximal fracture graft interface. Distal fracture was united with graft. Distal fragment was 
volarlv disblaced. It was later fixed with volar buttress Dlate and screws. Fracture was protected for 10 weeks in below elbow cast. The non-union of distal radius fracture is rare. Usuallv it is because of over distraction bv external fixators. ${ }^{25}$

\section{CONCLUSIONS}

We conclud that reduction of colles fracture can be done but maintaining in that position is problem. Open reduction and bone grafting is a useful method for the management of displaced Colles' fractures which prevents late collapse as compared to conventional casting. Functional results are comparable with the conventional cast application at least for the short term if significant malunion is avoided. Late comblications of malunion as carpal instabilitv and wrist arthrosis could not be assessed because of short term follow up. This procedure is invasive and adds bone donor site morbiditv which can be considered as drawback.

\section{REFERENCES}

1. Coonev WP III. Dobvns IH. Linscheid RL. Complications of Colles' fracture. I Bone Ioint Surø Am. 1980:62:613-9.

2. Chapmen DR.. Bennet IB. Brvan WI. Tullos HS. Complications of distal radial fractures. Pins and plaster treatment. I Hand Surg. 1982:7:509-12.

3. McBirnie I. Court-Brown CM. McOueen MM. Earlv open reduction and bone orafting for unstable fractures of the distal radius. I Bone Ioint Sur $\sigma$ Br. 1995:77:571-5.

4. LindenVD. Ericson R. Colles fracture. How should its displacement be measured and how should it be immobilized? I Bone Ioint Suro. Am 1981:63:1285-8.

5. Fernandez DL. Correction of post-traumatic wrist deformitv in adults bv osteotomv. bone grafting and internal fixation. I Bone Ioint Suro Am. 1982:64:1164-78.

6. Castain $\sigma$ I. Les fractures recentes de l'extremite' inferieure du radius chez l'adulte. Rev Chir Orthop. 1964:50:581-96.

7. Coonev WP. Linscheid RL. Dobvns IH. External pin fixation for unstable Colles' fractures. I Bone Ioint Sur $\sigma$ Am. 1979:61:840-5.

8. Frvkman G. Fracture of the distal radius includin $\sigma$ seauelae shoulderhand- finoer svndrome. disturbance in the distal radioulnar ioint and impairment of nerve function. A clinical and experimental studv. Acta Orthop Scand Supbl. 1967:108:1-155.
9. Colles A. On the fracture of the carnal extremitv of the radius. Edinburoh Med Suro I. 1814:10:182.

10. Green DP. Pin and plaster treatment of comminuted fractures of the distal end of the radius. I Bone Ioint Surg Am. 1975:57:304310 .

11. Lucas GL and Sachtien KM. An analvsis of hand function in patients with Colles' fractures treated bv Rush rod fixation. Clin Orthop Relat Res. 1981:155:172-9.

12. Gartland II and Werlv C. Evaluation of healed Colles' fractures. I Bone Ioint Suro Am. 1951:33:895-907.

13. Smaill GB. Long-term follow-up of Colles' fractures. I Bone Ioint Suro Br. 1965: 47:82-5.

14. Pogue DI. Viegas SF. Patterson RM. et al. Effects of distal radius fracture malunion on wrist ioint mechanics. I Hand Suro [Aml. 1990: 15:721-7.

15. Short WH. Palmer AK. Werner FW. et al. A biomechanical studv of distal radial fractures. I Hand Surg IAml. 1987:12:529-34.

16. Taleisnik I. Watson HK. Midcarnal instabilitv caused bv malunited fractures of the distal radius. I Hand Suro [Aml. 1984: 9:350-7.

17. Petersen MS. Adams BD. Biomechanical evaluation of distal radioulnar reconstructions. I Hand Sur $\sigma$ IAml. 1993: 18:328-34.

18. Bartosh RA. Saldana MI. Intraarticular fractures of the distal radius: a cadaveric studv to determine if liøamentotaxis restores radiopalmar tilt. I Hand Suro [Aml. 1990 Ian:15(1):18-21.

19. Coonev WP. Linscheid RL. External pin fixation for unstable colles fracture. I Bone Ioint Surg Am. 1979: 61:840-5.

20. McOueen MM. MacLennan W. Latta L. Fractures of distal radius in elderlv people. Skeletal trauma in old age. London: Chapman \& Hall1994: p. 109-23.

21. Kellv AI. Warwick D. Crichlow TP. Bannister GC. Is manibulation of moderatelv displaced colles fracture worthwhile? Iniurv. 1997:28:283-7.

22. Cassidv C. Iupiter IB et al. Norian SRS cement compared with conventional fixation in distal radius fracture. a randomized studv. I Bone Ioint Surg Am. 2003:85:2127-37.

23. McOueen MM. Casper I. Colles fracture: Does the anatomical result affect final function? I Bone Ioint Suro Br. 1988:70:64951.

24. Villar RN. Marsh D. Rushton N. Greatorex RA. Three vears after colles fracture. A prospective review. I Bone Ioint Sur $\sigma$ Br. 1987: 69:635-8.

25. Prommersberger KI. Fernandes DL. Non-union of distal radius fractures. Clin Orthon Relat Res. 2004:419:51-6. 